\title{
Leveraging ACRL's value of information frame in dealing with infodemics in a post-truth era
}

A $\mathrm{n}$ infodemic can be defined a disproportionate aggregate of information regarding a problem that makes exposure to reality challenging in a manner that compromises logical thinking. It can also be categorized as a pervasive and deliberatespread of misinformation geared towards deceiffulness. In the 1st WHO Infodemiology Conference, it was affirmed in the context of the coronavirus pandemic that infodemic had heightened deception to the point that necessitates a harmonized response because of the overabundance of misinformation that the world is inundated with, so much so that finding dependable sources and reliable guidance when urgently needed has become an uphill task. Consequently, misinformation blows out of proportion at a remarkably faster pace and further compounded the complexity to health emergency response. The abundance of information on social media oftentimes without authentic sources leads to a dilemma in distinguishing facts, mere opinions, propaganda, or prejudices. Social media has become an avenue for all sorts of misinformation that initially seems credible but later proves fraudulent. Conversely, by the time the authenticity is confirmed to be false, the damage may be irreversible. ${ }^{1}$

COVID-19 is a communicable disease triggered by a newly revealed virus. Those who are afflicted with this illness have shown, with available evidence, that they will experience mild to moderate symptoms and attain full recovery, even without any special treatment. ${ }^{2}$ However, for those with severesymptoms, having access to reliable information in terms of a treatment regime may bea lifesaver. According to J. Kang-Xing, ensuring access to accurate information and eliminating destructive contents, saturating social media with credible information, combating misinformation in all the social media platforms, empowering news media with an investment that will support prompt ability to factcheck information and prohibiting manipulative strategies and maneuvers in an advertisement that will cause panic or misinformation are ways to manage misinformation. ${ }^{3}$
The COVID-19 pandemic has elicited misinformation and conspiracy theories about the source, prevention, diagnosis, and treatment of the disease. Alternative facts, unconventional fabrication, and intentional disinformation have been presented, especially on social media about this disease, mainly from mischief-makers who are not well informed about the disease drowning out reality.

\section{Librarians' management of infodemics}

The tragedy of the COVID-19 pandemic has provided yet another occasion for libraries to re-affirm the crucial role of fighting any form of information disorder like an infodemic. Worldwide efforts have been geared towards ameliorating the health problems caused, which has opened another vista of opportunity to marshal quality knowledge towards the goodwill of saving humanity. ${ }^{4}$ The quality of information available to an individual can go a long way to reduce uncertainty, indecision, and manage panic. $^{5}$ This where the ACRL Framework for Information Literacy for Higher Education's frame on the value of information becomes highly essential in correcting half-baked misinformation in the face of a challenging global health pandemic. Librarians must mobilize their strategies to reflect a true belief and practice that truly "Information possesses several

Oluwole O. Durodolu is in the Department of Information Science, University of South Africa-Pretoria, email:woledurodolu@gmail.com, Samuel Kelechukwu Ibenne is in the Department of Library and Information Science, Abia State University-Uturu, in Nigeria, email: samuelibenne@gmail.com, and Tinyiko Vivian Dube is in the Department of Library and Information Services, University of South Africa-Pretoria, email: tinyikov@ hotmail.com

(C) 2021 Oluwole O. Durodolu, Samuel Kelechukwu Ibenne, and Tinyiko Vivian Dube 
dimensions of value, including ... [specifically] as a means of education, as a means to influence, and as a means of negotiating and understanding the world." ${ }^{\circ}$

This precarious situation of the ongoing COVID-19 pandemic should activate the consciousness of librarians to channel all their available resources to continue combatting the pandemic by making truthful and genuine information available and educating the populace about the danger of spreading misinformation, especially in the time of health emergencies. The knowledge of information literacy remains one of the potent weapons to combat misinformation. Information literacy has been appropriately likened to what a compass is to a sailor, information proliferation calls for appropriate knowledge of locating correct information from various sources. ${ }^{7}$

Additionally, information literacy affords an individual the ability to attain personal, collective, learning, and work-related goals, which are essential for countering the hazard of fake news in society today. ${ }^{8}$ An information literate citizen is equipped with the ability to determine the genuineness and trustworthiness of information, by using entrenched and valuable evaluative benchmarks to guarantee that people are sufficiently knowledgeable about information literacy to conquer the menace of fake and adulterated news. Deliberating on circumstances surrounding infodemic has preoccupied librarians, but regardless of the awareness of this problem, it is evidence that they have not been clear about the scope and nature of the predicament. A better understanding of the problem(s) may be crucial, nevertheless, not only for planning clarifications but also for matching a given problem with an adequate solution. ${ }^{?}$

\section{Conclusion}

The advent of COVID-19 has led to the proliferation of false and misleading information, oftentimes compromising the ability to access genuine health information and putting people's lives at risk and generating undue panic. In a post-truth era, where misleading information has been aggravated, it is important for the citizen to acquire new mental costumes in dealing with the issue. Library and educational institutions have highlighted various information literacy strategies to have a more information literate society, where citizens will have the capacity to evaluate information and identify fake news.

\section{Notes}

1. S. B. Naeem and R. Bhatti, "The Covid-19' infodemic': A new front for information professionals," Health Information and Libraries Journal, https://doi.org/10.1111/hir.12311.2020, YouTube video, https://www.youtube.com /watch?v=t1LXD2jo5-o.

2. World Health Organisation, First WHO Infodemiology Conference, June 30 -July 16, 2020, retrieved September 18 2020, from https://www. who.int/news-room/events/detail/2020/06/30 /default-calendar/1st-who-infodemiology-conference.

3. J. Kang-Xing, "Keeping People Safe and Informed About the Coronavirus," retrieved August 9, 2020, https://about.fb.com/news/2020/08 /coronavirus/.

4. C. T. Chisita, "Libraries in the midst of the Coronaᄀvirus (COVID-19): Researchers' experiences in dealing with the vexatious infodemic," Library Hi Tech News 37 (6), 11-14, https://doi. org/10.1108/LHTN-03-2020-0022.

5. R. Srinivasan, "The Role of Information is to Reduce Uncertainty," retrieved September 18, 2020, from https://iterativepath.wordpress. com/2010/06/15/the-role-of-information-is-to -reduce-uncertainty/.

6. ACRL, Information Literacy for Higher Education Framework, retrieved October, 24, 2020 from, www.ala.org/acrl/files/issues/infolit /framework.pdf.

7. O. O. Durodolu and D. O. Ocholla, "Search Strategy, Self-Concept and Metacognitive Skills of Secondary School Teachers in Selected Cities in Nigeria and South Africa," LIBRI: International Journal of Library and Information Science 67 (2), https://doi:10.1515/libri-2016-0104.

8. O. O. Durodolu and S. K. Ibenne, "The fake news infodemic vs information literacy," Library Hi Tech News 37 (7): 13-14, https://doi. org/10.1108/LHTN-03-2020-0020.

9. M. C. Sullivan, "Libraries and Fake News: What's the Problem? What's the Plan? Communications in Information Literacy 13 (1): 91-113, https://doi.org/10.15760/comminfolit. 2019.13.1.7. 2 